\title{
Blocking Screw-assisted Intramedullary Nailing Using the Reverse-rule-of-thumbs for Limb Lengthening and Deformity Correction
}

\author{
Sherif Dabash ${ }^{1}$, David T Zhang ${ }^{2}$, S Robert Rozbruch ${ }^{3}$, Austin T Fragomen ${ }^{4}$
}

\begin{abstract}
Introduction: Historically, blocking screws have been used to assist in acute reduction of fractures during intramedullary (IM) nailing. The reverse-rule-of-thumbs (RROT) for blocking screws was introduced to facilitate internal lengthening nail use in deformity correction and limb lengthening. Our study investigated the ability of blocking screws, using same principle, to accurately correct long-bone deformity with and without lengthening and to prevent lengthening-induced deformity.

Materials and methods: This is an institutional review board (IRB)-approved retrospective study on 86 patients who had IM nail-assisted limb reconstruction of femur or tibia with blocking screws. Surgeries were performed for deformity correction, limb lengthening, or deformity correction and limb lengthening. Data on the following variables were collected: number of blocking screws, distance of each blocking screw to osteotomy, distance of osteotomy from joint line, and amount of lengthening. Mechanical axis deviation (MAD) and joint alignment parameters were measured preoperatively and at the final postoperative follow-up. The primary outcome was the ability to obtain desired MAD and joint orientation angles. Accuracies were reported as postoperative measurements relative to goal. Association for the Study and Applications of the Methods of Ilizarov (ASAMI) scores were collected.

Results: The accuracy of deformity correction was within $6 \mathrm{~mm}$ from goal, while joint orientation was corrected to within $1.5^{\circ}$ of goal. Number of blocking screws did not significantly impact accuracy. Distance of blocking screw to osteotomy and amount of lengthening did not affect accuracy. In femurs, osteotomies greater than $10 \mathrm{~cm}$ from the joint line were more accurate in MAD goal $(p=0.017)$. This result was not replicated in tibias. ASAMI scores were excellent or good.

Conclusion: Using RROT configuration, blocking screws were effective in correcting deformities of lower extremity long bones and in preventing deformity during limb lengthening. If positioned correctly, number of screws and their distance to osteotomy did not affect accuracy. Amount of lengthening did not impact accuracy. Distal femoral osteotomy less than $10 \mathrm{~cm}$ from knee joint may be challenging even with using blocking screws.

Keywords: Blocking screw, Deformity correction, Internal lengthening nail, Intramedullary nail, Limb lengthening, Poller screw, Precice.

Strategies in Trauma and Limb Reconstruction (2019): 10.5005/jp-journals-10080-1430
\end{abstract}

\section{INTRODUCTION}

Blocking (Poller) screws have been shown to assist in the acute reduction of long-bone fractures and fracture malunions during intramedullary (IM) nailing. ${ }^{1-5}$ Fractures and deformities of the proximal third of the tibia and distal third of the femur are particularly well suited for blocking screw-assisted reduction. ${ }^{4,6}$ The multi-point fixation of the IM nail provided by blocking screws has been shown to decrease deformation by up to $57 \%$ in distal tibia fractures. ${ }^{7}$ In cases of post-traumatic and congenital deformities, IM nails have been used increasingly for realignment, and blocking screws have greatly improved control of the bone fragments. When deformities are accompanied by limb shortening, IM lengthening nails can be used to correct the malalignment and distract through the osteotomy site. In these cases, and in cases of simple IM lengthening without deformity, blocking screws have been seen to prevent any additional deformity from occurring during the lengthening process. ${ }^{8}$ We have previously reported on the successful use of blocking screws for the simultaneous correction of angular deformity and lengthening of the distal femur. ${ }^{9}$ In this setting, blocking screws effectively assisted with acute deformity correction and prevent the progression of deformity as lengthening proceeds. ${ }^{3,4}$

The reverse-rule-of-thumbs (RROT) was introduced to simplify the process of deciding where to place blocking screws to achieve

\begin{abstract}
${ }^{1-4}$ Department of Orthopaedic Surgery, Limb Lengthening and Complex Reconstruction Service, The Hospital for Special Surgery, New York, USA; Department of Orthopaedic Surgery, Weill Medical College of Cornell University, The Hospital for Special Surgery, New York, USA

Corresponding Author: Austin $T$ Fragomen, Department of Orthopaedic Surgery, Limb Lengthening and Complex Reconstruction Service, The Hospital for Special Surgery, New York, USA; Department of Orthopaedic Surgery, Weill Medical College of Cornell University, The Hospital for Special Surgery, New York, USA, Phone: +1 212-6061550, e-mail: FragomenA@hss.edu
\end{abstract}

How to cite this article: Dabash S, Zhang DT, Rozbruch SR, et al. Blocking Screw-assisted Intramedullary Nailing Using the Reverserule-of-thumbs for Limb Lengthening and Deformity Correction. Strategies Trauma Limb Reconstr 2019;14(2):77-84.

Source of support: Nil

Conflict of interest: None

the desired alignment. ${ }^{9}$ It is more comprehensive than the common guideline of simply placing the screws in the concavity of the deformity (Fig. 1). There are instances where no blocking screw is needed such as when the nail is pressed against the cortex at a site where a blocking screw should be considered (based on the RROT), but there is no space to insert the screw (Fig. 2). The current study 
investigated the ability of IM nailing with blocking screws, using the principle of the RROT, to accurately correct long-bone deformity with and without lengthening and to prevent lengthening-induced deformity. The effect of several variables, including the number of screws used, the proximity of the osteotomy to the joint line, and

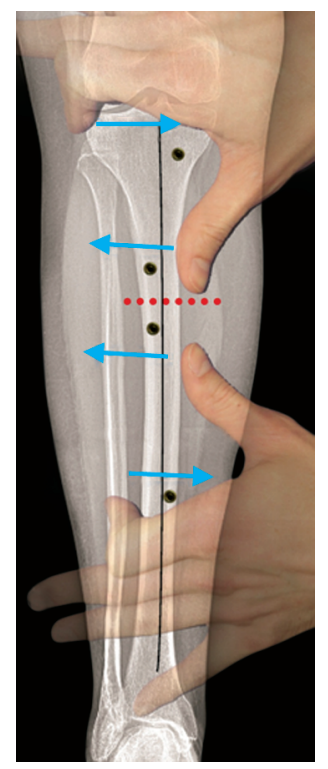

Fig. 1: The RROT for placing blocking screws is demonstrated. This preoperative radiograph shows a mild valgus deformity in a tibia that requires lengthening surgery. The thumbs and index fingers are placed in the intuitive orientation to correct the deformity with the thumbs in the convexity. The blocking screws are inserted opposite from the finger positions to ensure deformity correction with the IM nail. The dotted red line represents the site of our osteotomy the amount of bone lengthening, on the accuracy of deformity correction was analysed.

\section{Materials and Methods}

\section{Surgical Technique}

Preoperative planning was performed for all cases using calibrated anterior-posterior (AP) and lateral radiographs of the bone to be operated upon (femur or tibia) and a standing hip-to-ankle radiograph. The deformity apex was localised and quantified, and the osteotomy site was selected using a digital radiographic planning technique with IM nail templates (Sectra, Linkoping, Sweden).$^{10}$ The optimal position, width, and length of the IM nail were determined. Blocking screw position was selected using the RROT. The desired postoperative mechanical axis and joint orientation angles were selected prior to surgery.

Surgery was performed under regional anesthesia. In cases of deformity correction, blocking screws were placed in the preplanned position under fluoroscopy to facilitate passage of the guidewire and direct the flexible reamer in the IM canal (Fig. 3). In cases of lengthening without deformity correction, the IM nails were implanted, and the blocking screws were then inserted afterward in order to prevent anticipated deformity during lengthening. Blocking screws were placed strategically with the goal of directly contacting the IM nail to prevent movement of the nail in an unwanted direction. For deformity correction alone, standard titanium trauma nails were used, and for lengthening with or without deformity correction, the Precice (NuVasive, Irvine, CA) IM lengthening nail was used. Nail diameter was selected based on the IM canal diameter at the isthmus. Blocking screws were all 4-5 $\mathrm{mm}$ in diameter. Flexible reamers were used to dilate the IM canal. Static nails were over-reamed by $1.5 \mathrm{~mm}$ and lengthening nails by $2.0 \mathrm{~mm}$. Weight bearing (WB) was allowed ad lib for most corrections with trauma nails. The internal lengthening nail
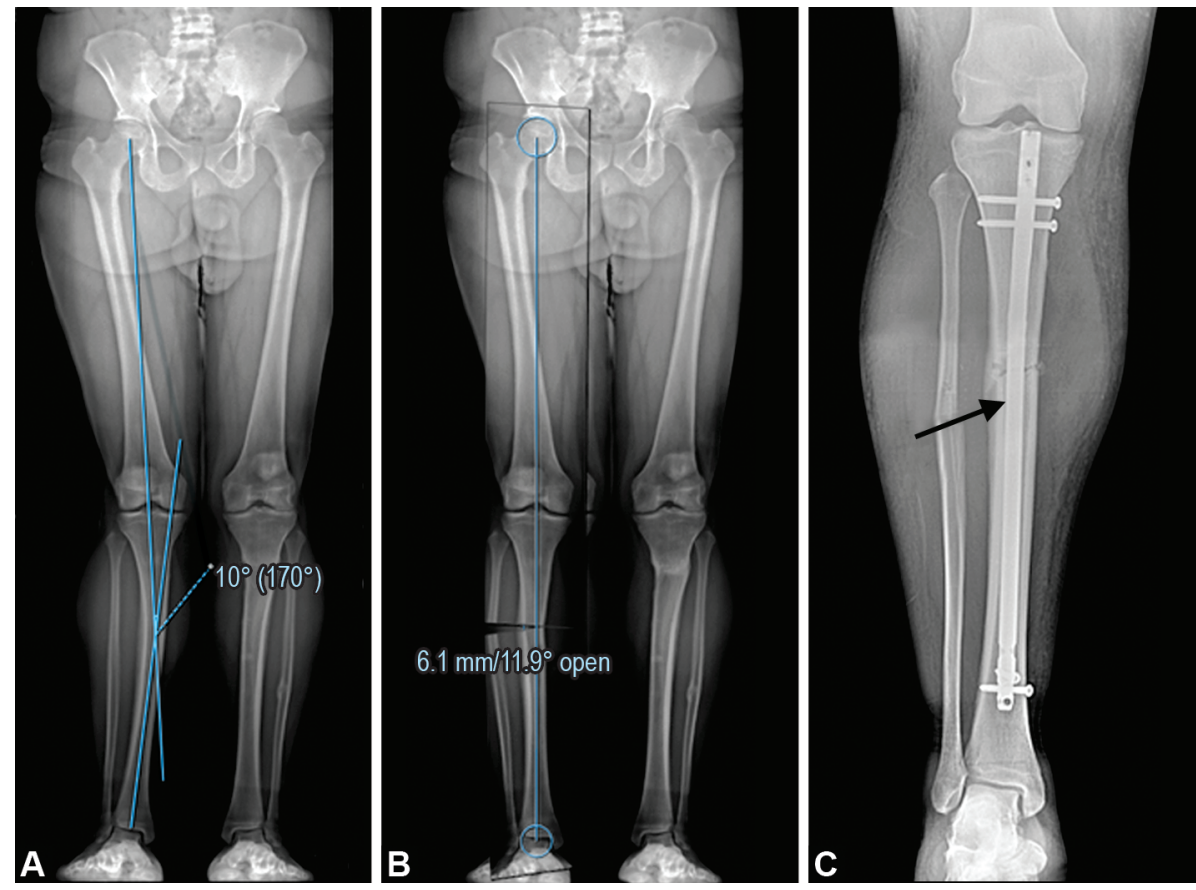

Figs 2A to C: (A) A valgus deformity is localised to the proximal tibia; (B) The preoperative plan shows that an IM nail can correct the deformity, reestablishing a normal mechanical axis; (C) This postoperative radiograph shows no blocking screw was used. The IM nail is pressed directly against the lateral cortex in the distal fragment (arrow) making blocking screw placement unnecessary 

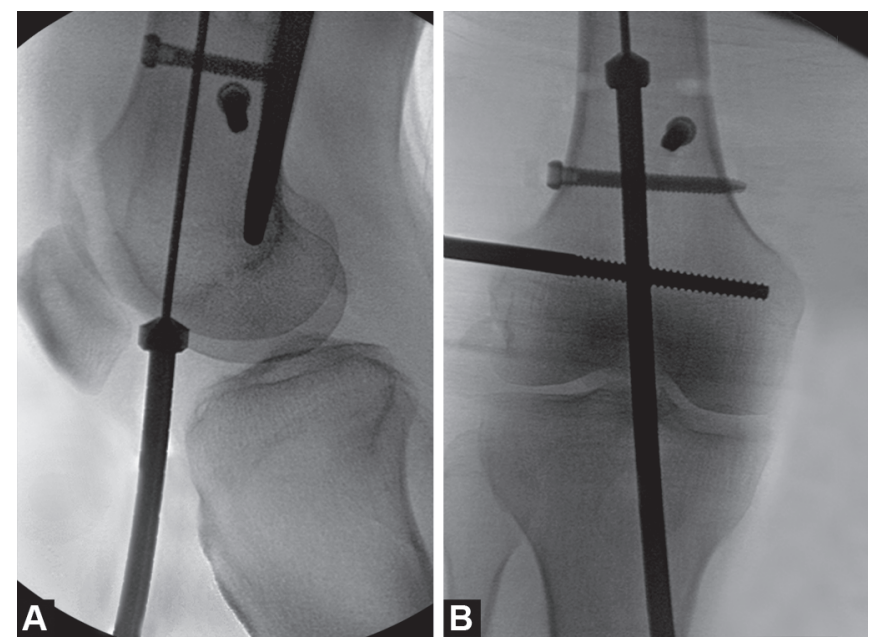

Figs $3 A$ and $B$ : (A) The blocking screws are placed prior to reaming. The guide wire is advanced in the optimal direction; (B) A short, rigid reamer is directed over the guidewire and past the osteotomy site. This is soon replaced by a long wire and flexible reamers

demands strict adherence to a prescribed, protective WB protocol. Venous thromboembolism prophylaxis consisting of rivaroxaban or enoxaparin was started on postoperative day 2 for all patients and continued for 2 weeks.

Flexion deformity at a periarticular osteotomy site can be introduced either at the time of IM nail insertion or during the lengthening process. Posterior blocking screws were placed prior to reaming in tibial osteotomy cases and either before or after IM nail insertion in retrograde femur cases. In cases of lengthening, a posterior blocking screw was inserted if the space between the IM nail and the inner cortex of the bone was $5 \mathrm{~mm}$ or greater. In cases where the space was less, and a screw would not fit, the cortex itself would act as a block to flexion. The same logic was used for the correction of varus and valgus in the coronal plane: when there was no space for a screw (commonly the case in the diaphyseal fragment), it was reasoned that the bone would be unable to drift into a deformity.

\section{Postoperative Period}

Patients had different protocols for WB according to the surgery done. For deformity correction, titanium trauma nails used allow $50 \%$ partial WB status of the patients for 6 weeks than weight bearing as tolerated (WBAT). For limb lengthening, the Precice (NuVasive) IM lengthening nail was used which has three different diameters (8.5, 10.7, and 12.5) and tolerates specific loads; size 8.5 allows 30 pounds PWB; size 10.7 allows 50 pounds PWB, and size 12.5 allows 70 pounds partial weight bearing (PWB). Blocking screws did not change our WB protocol. Those WB restrictions continued until healing of two cortices in the consolidation phase and then the patients were allowed to WBAT.

\section{Data Analysis}

We conducted an institutional review board (IRB)-approved retrospective case series on 86 patients who had IM nail-assisted limb reconstruction with blocking screws. These surgeries were performed for three different indications: (1) deformity correction, (2) limb lengthening, or (3) deformity correction and limb lengthening. Data on the following variables were collected: number of blocking screws used and the position of these screws

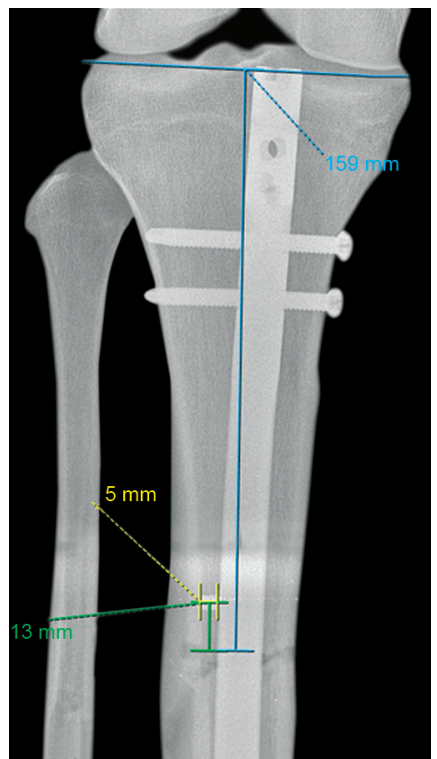

Fig. 4: This radiograph shows how data were collected including distance of the osteotomy from the joint $(159 \mathrm{~mm})$, distance from the nail to the inner cortex at the site of the blocking screw $(5 \mathrm{~mm})$, and distance from the blocking screw to the osteotomy $(13 \mathrm{~mm})$

including their distance to the osteotomy, distance from the IM nail to the closest inner cortex at the level where a blocking screw should be considered as dictated by the RROT, distance from the joint line to osteotomy, and the amount of limb lengthening (Fig. 4). We measured mechanical axis deviation (MAD), lateral distal femoral angle (LDFA), medial proximal tibial angle (MPTA), posterior distal femoral angle (PDFA), and posterior proximal tibial angle (PPTA), preoperatively and postoperatively. The ability to obtain the desired MAD after correction or lengthening was used to judge the accuracy of the technique in cases where only one bone (femur or tibia) was operated on. The primary outcome in femurs was the ability to obtain the desired LDFA and PDFA and in tibias the desired MPTA and PPTA. We also measured the posterior canal space between the IM nail and the inner cortex at the level of all posterior blocking screws both before and after distraction to observe subtle flexion that might otherwise be missed by sagittal joint orientation angle measurement alone. A secondary outcome was the Association for the Study and Applications of the Methods of Ilizarov (ASAMI) score. ${ }^{11}$

The preoperative goals were chosen for MAD, LDFA, MPTA, PDFA, and PPTA. These were done based on the preoperative planning which was saved into the hospital radiographic system. We calculated accuracy based on the following formulas:

$$
\begin{aligned}
\text { Accuracy } & =1-\text { Error } \\
\text { where Error } & =\frac{\text { Postoperative }- \text { closer of normal limit bounds }}{\text { Preoperative }- \text { median of normal limits }} .
\end{aligned}
$$

The normal limits were defined by Paley ${ }^{12}$ as MAD (12 mm range from neutral alignment, either 6 lateral or 6 medial), LDFA $\left(85-90^{\circ}\right)$, MPTA $\left(85-90^{\circ}\right)$, PDFA $\left(79-87^{\circ}\right)$, and PPTA $\left(77-84^{\circ}\right)$. We then compared the outcomes based on the three types of surgical indications. We also analysed how different variables affected the final alignment. It was hypothesised that an increasing number of blocking screws would improve accuracy, that increasing distance of the osteotomy from the joint line would allow the IM nail to 
control the segments better and would improve accuracy, and that increasing amounts of lengthening would lead to more deformity and poorer accuracy. Thresholds were selected for these variables based on clinical perception and the median for the group being analysed. This allowed for analysis of two groups (on either side of the threshold) for each variable.

\section{Statistics}

All statistical analyses were performed in Microsoft Excel (Microsoft ${ }^{\circledR}$ Excel for Mac 2019). We used a Student's $t$ test to compare results between two groups and analysis of variance to compare three groups. The significance level was chosen to be 0.05 , and any $p$ value less than that was deemed significant.

\section{Results}

Eighty-six patients (46 femurs and 40 tibias) were included in this study (Table 1). Mechanical axis deviation improved to within a mean of $6.1 \mathrm{~mm}$ from the goal with an accuracy of 91\% (Table 2). Mechanical axis deviation goal was determined pre-operative and was not always zero as in some cases under- or overcorrection was desirable. In femur cases, the LDFA corrected to a mean of $1.4^{\circ}$ from the goal in valgus deformities and $1.5^{\circ}$ in varus deformities. The PDFA corrected to a mean of $1.3^{\circ}$ from goal (Table 3 ). In tibia cases, the MPTA corrected to a mean of $1.6^{\circ}$ from goal for both valgus and varus deformities, and the PPTA corrected to a mean of $1.6^{\circ}$ from goal (Table 4). The accuracies of the angular corrections ranged between $97 \%$ and $100 \%$ (Table 5). No significant difference was detected when comparing outcomes between deformity correction, deformity correction and lengthening, and lengthening alone $(p=0.404)$.

Table 1: Demographics

\begin{tabular}{lll}
\hline & $n$ & Mean (range) \\
\hline All & & \\
Age (years) & 86 & $38.4(10-71)$ \\
BMI $\left(\mathrm{kg} / \mathrm{m}^{2}\right)$ & 82 & $28.1(6.7-47.4)$ \\
$\quad$ Female (\%) & 38 & 44.2 \\
Femurs & & \\
Age (years) & 46 & $37.9(10-63)$ \\
BMl (kg/m $\left.{ }^{2}\right)$ & 46 & $27.5(6.7-47.4)$ \\
Female (\%) & 46 & 43.5 \\
Tibias & & \\
Age (years) & 40 & $38.9(16-71)$ \\
BMI (kg/m $\left.{ }^{2}\right)$ & 36 & $28.9(14.2-47.4)$ \\
Female (\%) & 40 & 39.1 \\
\hline
\end{tabular}

BMI, body mass index

Table 2: Mechanical axis deviation (MAD) metrics

\begin{tabular}{|c|c|c|c|}
\hline & $\begin{array}{l}\text { MAD } \\
\text { preoperative } \\
(\mathrm{mm}) \text { (range) }\end{array}$ & $\begin{array}{l}\text { MAD goal }(\mathrm{mm}) \\
(S D)\end{array}$ & $\begin{array}{l}\text { MAD } \\
\text { postoperative- } \\
\text { goal }(\mathrm{mm})(\mathrm{SD})\end{array}$ \\
\hline All $(n=55)$ & $\begin{array}{l}20.0 \text { ( } 68 \text { medial } \\
\text { to } 33 \text { lateral) }\end{array}$ & $2.1(4.0)$ & $6.1(5.8)$ \\
\hline Femurs $(n=29)$ & $\begin{array}{l}22.5 \text { ( } 68 \text { medial } \\
\text { to } 31 \text { lateral) }\end{array}$ & $2.6(4.6)$ & $5.3(5.3)$ \\
\hline Tibias $(n=26)$ & $\begin{array}{l}17.2 \text { ( } 34 \text { medial } \\
\text { to } 33 \text { lateral) }\end{array}$ & $1.7(3.4)$ & $6.9(6.4)$ \\
\hline
\end{tabular}

$\mathrm{SD}$, standard deviation
The alignment parameters were also compared between casedependent factors including number of blocking screws, distance from osteotomy to joint line, and amount of lengthening. In the femur surgery group, patients with an osteotomy greater than 10 $\mathrm{cm}$ from the joint line achieved an MAD that was significantly closer to goal than patients with an osteotomy less than or equal to 10 $\mathrm{cm}$ from the joint line $(p=0.017)$. However, in the same surgical patients, the final LDFA that resulted from surgery yielded a similar accuracy ( $p=0.48$ ) (Table 6$)$. Additionally, in the femur surgery group, patients with one or more posterior blocking screw(s) had a significantly smaller change in the posterior canal space compared with those who did not have any posterior blocking screws (0.4 vs $1.0 \mathrm{~mm}, p=0.037$ ) (Table 7).

Analysis of the same variables was performed on the tibia osteotomy patients (Tables $8-10$ ). Some tibial reconstruction patients sustained a posterior cortical fracture during proximal tibial osteotomy where the osteotomy fracture propagated cephalad either compromising the posterior blocking screw or forcing the screw to be inserted more proximally than ideal (Fig. 5). These patients had significantly greater posterior canal spaces (between

Table 3: LDFA and PDFA metrics for femoral reconstruction

\begin{tabular}{llll}
\hline & $\begin{array}{l}\text { LDFA } \\
\text { preoperative }\left(^{\circ}\right) \\
(\text { range })\end{array}$ & $\begin{array}{l}\text { LDFA goal }\left({ }^{\circ}\right) \\
(S D)\end{array}$ & $\begin{array}{l}\text { LDFA } \\
\text { postoperative- } \\
\text { goal }\left({ }^{\circ}\right)(S D)\end{array}$ \\
\hline Valgus $(n=23)$ & $83.0(75-87)$ & $88.2(2.7)$ & $1.4(1.2)$ \\
Varus $(n=23)$ & $97.3(89-118)$ & $89.7(2.3)$ & $1.5(1.5)$ \\
\hline & $\begin{array}{l}\text { PDFA } \\
\text { preoperative }\left(^{\circ}\right)\end{array}$ & PDFA goal $\left(^{\circ}\right)$ & $\begin{array}{l}\text { PDFA } \\
\text { postoperative- } \\
\text { goal }\left({ }^{\circ}\right)\end{array}$ \\
& $83.1(63-102)$ & $84.5(3.2)$ & $1.3(1.5)$ \\
\hline $\begin{array}{l}\text { All femurs } \\
(n=46)\end{array}$ & & \\
\hline
\end{tabular}

SD, standard deviation; LDFA, lateral distal femoral angle; PDFA, posterior distal femoral angle

Table 4: MPTA and PPTA metrics for tibial reconstruction

\begin{tabular}{llll}
\hline Tibias & $\begin{array}{l}\text { MPTA } \\
\text { preoperative }\left({ }^{\circ}\right) \\
(\text { range })\end{array}$ & $\begin{array}{l}\text { MPTA goal }\left({ }^{\circ}\right) \\
(S D)\end{array}$ & $\begin{array}{l}\text { MPTA } \\
\text { postoperative- } \\
\text { goal }\left({ }^{\circ}\right)(S D)\end{array}$ \\
\hline Varus $(n=11)$ & $82.9(80-87)$ & $87.6(1.9)$ & $1.6(1.5)$ \\
Valgus $(n=29)$ & $92.6(88-99)$ & $87.8(1.9)$ & $1.6(1.4)$ \\
\hline & $\begin{array}{l}\text { PPTA } \\
\text { preoperative }\left({ }^{\circ}\right)\end{array}$ & ${\text { PPTA goal }\left({ }^{\circ}\right)}^{\text {PPTA }}$ \\
& & $\begin{array}{l}\text { postoperative- } \\
\text { goal }\left({ }^{\circ}\right)\end{array}$ \\
\hline $\begin{array}{l}\text { All tibias } \\
(n=40)\end{array}$ & $79.2(70-88)$ & $80.0(3.2)$ & $1.6(2.4)$ \\
\hline
\end{tabular}

All values reported as mean (range) or mean (SD); SD, standard deviation; MPTA, medial proximal tibial angle; PPTA, posterior proximal tibial angle

Table 5: Accuracy of blocking screw technique

\begin{tabular}{llc}
\hline Measurement & $n$ & $\begin{array}{l}\text { Mean accuracy } \\
\text { (range) }\end{array}$ \\
\hline MAD & 53 & $91.6 \%(25.0-100.0)$ \\
LDFA & 46 & $97.0 \%(62.5-100.0)$ \\
MPTA & 36 & $97.0 \%(50.0-100.0)$ \\
PDFA & 45 & $99.6 \%(83.3-100.0)$ \\
PPTA & 34 & $100.0 \%(100.0-100.0)$ \\
\hline
\end{tabular}

LDFA, lateral distal femoral angle; PDFA, posterior distal femoral angle; MPTA, medial proximal tibial angle; PPTA, posterior proximal tibial angle; $M A D$, mechanical axis deviation 
Blocking Screw-assisted Intramedullary Nailing Using the RROT for Limb Lengthening and Deformity Correction

Table 6: Effect of selected variables on femurs (coronal view/AP blocking screws)

\begin{tabular}{|c|c|c|c|c|c|c|}
\hline \multirow[b]{2}{*}{ Parameters (mean, range) } & \multicolumn{3}{|c|}{ MAD postoperative-goal $(\mathrm{mm})$} & \multicolumn{3}{|c|}{ LDFA postoperative-goal $\left({ }^{\circ}\right)$} \\
\hline & $n$ & Mean (range) & $p$ value & $n$ & Mean (range) & pvalue \\
\hline \multicolumn{7}{|c|}{ Number of coronal blocking screws } \\
\hline 1 blocking screw & 18 & $6.0(0-25)$ & 0.381 & 31 & $1.4(0-6)$ & 0.567 \\
\hline $2+$ blocking screw & 11 & $4.3(0-15)$ & & 15 & $1.6(0-4)$ & \\
\hline \multicolumn{7}{|c|}{ Osteotomy distance from joint line } \\
\hline$\leq 10 \mathrm{~cm}(8.5,6.0-9.8)$ & 15 & $7.6(1-25)$ & 0.017 & 25 & $1.6(0-6)$ & 0.484 \\
\hline$>10 \mathrm{~cm}(15.0,10.2-28.1)$ & 14 & $2.9(0-8)$ & & 21 & $1.3(0-4)$ & \\
\hline \multicolumn{7}{|l|}{ Amount of lengthening } \\
\hline$\leq 3.5 \mathrm{~cm}(2.3,1.4-3.0)$ & 13 & $4.6(0-15)$ & 0.492 & 20 & $1.4(0-4)$ & 0.830 \\
\hline$>3.5 \mathrm{~cm}(5.2,3.5-8.0)$ & 11 & $5.7(1-10)$ & & 19 & $1.3(0-4)$ & \\
\hline
\end{tabular}

LDFA, lateral distal femoral angle; MAD, mechanical axis deviation

Table 7: Effect of selected variables on femurs (sagittal view/posterior blocking screws)

\begin{tabular}{|c|c|c|c|c|c|c|}
\hline \multirow[b]{2}{*}{ Parameters (mean, range) } & \multicolumn{3}{|c|}{ PDFA postoperative-goal $\left({ }^{\circ}\right)$} & \multicolumn{3}{|c|}{$\Delta$ Posterior canal space $(\mathrm{mm})$} \\
\hline & $n$ & Mean (range) & $p$ value & $n$ & Mean (range) & $p$ value \\
\hline \multicolumn{7}{|c|}{ Number of sagittal blocking screws } \\
\hline 0 blocking screw & 34 & $1.4(0-5)$ & 0.479 & 29 & $1.0(0-3)$ & 0.037 \\
\hline $1+$ blocking screw & 12 & $1.1(0-4)$ & & 10 & $0.4(0-2)$ & \\
\hline \multicolumn{7}{|c|}{ Osteotomy distance from joint line } \\
\hline$\leq 10 \mathrm{~cm}(8.5,6.0-9.8)$ & 25 & $1.4(0-5)$ & 0.653 & 22 & $0.7(0-3)$ & 0.165 \\
\hline$>10 \mathrm{~cm}(15.0,10.2-28.1)$ & 21 & $1.2(0-4)$ & & 17 & $1.1(0-3)$ & \\
\hline \multicolumn{7}{|l|}{ Amount of lengthening } \\
\hline$\leq 3.5 \mathrm{~cm}(2.3,1.4-3.0)$ & 20 & $1.5(0-5)$ & 0.872 & 20 & $0.9(0-3)$ & 0.852 \\
\hline$>3.5 \mathrm{~cm}(5.2,3.5-8.0)$ & 19 & $1.4(0-5)$ & & 19 & $0.8(0-3)$ & \\
\hline
\end{tabular}

PDFA, posterior distal femoral angle

Table 8: Effect of selected variables on tibias (coronal view/AP blocking screws)

\begin{tabular}{|c|c|c|c|c|c|c|}
\hline \multirow[b]{2}{*}{ Parameters (mean, range) } & \multicolumn{3}{|c|}{ MAD postoperative-goal $(\mathrm{mm})$} & \multicolumn{3}{|c|}{ MPTA postoperative-goal $\left({ }^{\circ}\right)$} \\
\hline & $n$ & Mean (range) & pvalue & $n$ & Mean (range) & $p$ value \\
\hline \multicolumn{7}{|c|}{ Number of coronal blocking screws } \\
\hline 1 blocking screw & 17 & $5.5(0-23)$ & 0.478 & 28 & $1.3(0-4)$ & 0.249 \\
\hline $2+$ blocking screw & 4 & $9.3(1-22)$ & & 6 & $2.2(1-5)$ & \\
\hline \multicolumn{7}{|c|}{ Osteotomy distance from joint line } \\
\hline$\leq 10 \mathrm{~cm}(9.0,7.7-9.9)$ & 6 & $10.5(0-23)$ & 0.316 & 7 & $1.4(0-3)$ & 0.782 \\
\hline$>10 \mathrm{~cm}(12.9,10.2-23.7)$ & 20 & $5.9(0-19)$ & & 33 & $1.6(0-5)$ & \\
\hline \multicolumn{7}{|l|}{ Amount of lengthening } \\
\hline$\leq 4 \mathrm{~cm}(3.0,2.1-3.9)$ & 6 & $5.0(0-10)$ & 0.666 & 9 & $1.6(0-3)$ & 0.552 \\
\hline$>4 \mathrm{~cm}(5.2,4.1-6.1)$ & 6 & $6.5(0-19)$ & & 7 & $2.0(0-5)$ & \\
\hline
\end{tabular}

MPTA, medial proximal tibial angle; MAD, mechanical axis deviation

the nail and the inner cortex) pre-distraction when compared with non-fracture cohort $(p<0.001)$ and postoperatively at the termination of lengthening $(p=0.017)$. Significant increases in the posterior canal space $(p<0.001)$ were observed in the fracture cohort when compared with those who did not experience posterior cortical, proximal fracture propagation. These patients also had a PPTA that was significantly further from goal when compared with those who did not experience posterior cortical fracture propagation ( $p=0.045$ ) (Table 10). Posterior proximal tibial angle seemed to be a more sensitive indicator of sagittal loss of alignment than change in posterior canal space. Distance from the osteotomy to the blocking screw was insignificant across all groups ( $p=0.316$ for MAD vs goal, $p=0.782$ for MPTA vs goal, $p=0.117$ for PPTA vs goal, and $p=0.647$ for change in posterior canal space).

ASAMI bone scores were excellent (95\%) or good for all patients, and ASAMI function scores were excellent (92\%) or good for all patients (Table 11).

\section{Discussion}

Blocking screw-assisted IM nailing is a well-established treatment for long-bone fractures. ${ }^{7,18-22}$ Intramedullary lengthening nails, in combination with blocking screws, have been successful in the treatment of limb deformity and limb length discrepancy. ${ }^{2-5,8}$ The 
Blocking Screw-assisted Intramedullary Nailing Using the RROT for Limb Lengthening and Deformity Correction

Table 9: Effect of selected variables on tibias (sagittal view/posterior blocking screws)

\begin{tabular}{|c|c|c|c|c|c|c|}
\hline \multirow[b]{2}{*}{ Parameters (mean, range) } & \multicolumn{3}{|c|}{ PPTA postoperative-goal $\left({ }^{\circ}\right)$} & \multicolumn{3}{|c|}{$\Delta$ Posterior canal space $(\mathrm{mm})$} \\
\hline & $n$ & Mean (range) & $p$ value & $n$ & Mean (range) & $p$ value \\
\hline \multicolumn{7}{|c|}{ Number of sagittal blocking screws } \\
\hline 0 blocking screw & 21 & 79.8 (70 to 87 ) & 0.104 & 6 & $0.5(0$ to 1$)$ & 0.194 \\
\hline $1+$ blocking screw & 19 & 80.1 (76 to 88 ) & & 10 & 0.8 (-2 to 3$)$ & \\
\hline \multicolumn{7}{|c|}{ Osteotomy distance from joint line } \\
\hline$\leq 10 \mathrm{~cm}(9.0,7.7$ to 9.9$)$ & 7 & 81.4 (79 to 87 ) & 0.117 & 2 & $1.5(0$ to 3$)$ & 0.647 \\
\hline$>10 \mathrm{~cm}(12.9,10.2$ to 23.7$)$ & 33 & 79.6 (70 to 88 ) & & 14 & $0.6(-2$ to 3$)$ & \\
\hline \multicolumn{7}{|l|}{ Amount of lengthening } \\
\hline$\leq 4 \mathrm{~cm}(3.0,2.1$ to 3.9$)$ & 9 & 79.9 (77 to 88$)$ & 1.000 & 9 & $0.6(0$ to 3$)$ & 0.607 \\
\hline$>4 \mathrm{~cm}(5.2,4.1$ to 6.1$)$ & 7 & 80.4 (76 to 87 ) & & 7 & $0.9(-2$ to 3$)$ & \\
\hline
\end{tabular}

PPTA, posterior proximal tibial angle

Table 10: Effect of tibial posterior cortical fracture with proximal propagation

\begin{tabular}{llclcr}
\hline & \multicolumn{2}{c}{ Fracture } & \multicolumn{2}{c}{ No fracture } \\
\cline { 2 - 5 } & $n$ & Mean (range) & $n$ & Mean (range) & $p$ value \\
\hline PPTA postoperative-goal $\left({ }^{\circ}\right)$ & 4 & $6.5(3$ to 11$)$ & 36 & $1.1(0$ to 7$)$ & 0.045 \\
Posterior canal space pre-distraction $(\mathrm{mm})$ & 3 & $11.3(11$ to 12$)$ & 13 & $5.3(0$ to 11$)$ & $<0.001$ \\
Posterior canal space post-distraction $(\mathrm{mm})$ & 3 & $10.3(8$ to 12$)$ & 13 & $5.0(0$ to 10$)$ & 0.017 \\
PPosterior canal space $(\mathrm{mm})$ & 3 & $1.0(0$ to 3$)$ & 13 & $0.6(-2$ to 3$)$ & $<0.001$ \\
\hline
\end{tabular}

PPTA, posterior proximal tibial angle

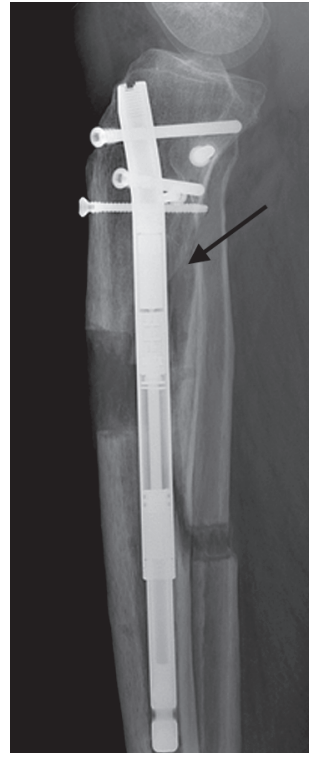

Fig. 5: A posterior cortical fracture occurred during the osteotomy and propagated into the proximal tibia (arrow) which forced the blocking screw to be placed too proximally. The tibia then flexed as it lengthened

proper placement of these screws can be confusing and is simplified with the RROT. ${ }^{9}$ The aim of this study was to critically assess the accuracy of blocking screw-assisted deformity correction and bone lengthening using the RROT guideline. The ability to achieve ideal alignment was measured for the whole group and then broken down into bone segment and surgical indication. Further scrutiny was directed toward nuanced variables including the technique's ability to control metaphyseal osteotomy alignment through lengthening. Our study demonstrated overall excellent accuracy. The lowest accuracy (92\%) was seen using the MAD metric, while the remainder of our accuracy measures using joint orientation
Table 11: ASAMI scores

\begin{tabular}{|c|c|c|}
\hline Bony results & Description & Number of patients \\
\hline Excellent & $\begin{array}{l}\text { Union, no infection, } \\
\text { deformity }<7 \text {, LLD }<2.5\end{array}$ & 82 \\
\hline Good & $\begin{array}{l}\text { Union + any two of the } \\
\text { following: no infection, } \\
\text { deformity }<7 \text {, } \\
\text { LLD }<2.5\end{array}$ & 4 \\
\hline Fair & $\begin{array}{l}\text { Union + any one of the } \\
\text { following: no infection, } \\
\text { deformity }<7 \text {, LLD }<2.5\end{array}$ & 0 \\
\hline Poor & $\begin{array}{l}\text { Nonunion/refracture/ } \\
\text { union/infection }+ \\
\text { deformity }>7 / \text { LLD }>2.5\end{array}$ & 0 \\
\hline Functional results & Description & Number of patients \\
\hline Excellent & $\begin{array}{l}\text { Active, no limp, minimum } \\
\text { stiffness (loss of }<15 \\
\text { knee extension/ }<15 \text { DF } \\
\text { of the ankle), no RSD, } \\
\text { insignificant pain }\end{array}$ & 79 \\
\hline Good & $\begin{array}{l}\text { Active with one or two } \\
\text { of the following: limp, } \\
\text { stiffness, RSD, significant } \\
\text { pain }\end{array}$ & 7 \\
\hline Fair & $\begin{array}{l}\text { Active with } 3 \text { or all } \\
\text { of the following: limp, } \\
\text { stiffness, RSD, significant } \\
\text { pain }\end{array}$ & 0 \\
\hline Poor & $\begin{array}{l}\text { Inactive (unemployment } \\
\text { or inability to return to } \\
\text { daily activities because of } \\
\text { injury) }\end{array}$ & 0 \\
\hline Failure & Amputation & 0 \\
\hline
\end{tabular}

LLD, limb length discrepancy; DF, dorsiflexion; RSD, reflex sympathetic dystrophy 
Table 12: Relevant literature on motorised internal lengthening nail results

\begin{tabular}{|c|c|c|c|}
\hline Lead author & $\begin{array}{l}\text { Accuracy of deformity } \\
\text { correction }\end{array}$ & BHI (days/cm) & $\begin{array}{l}\text { Total } \\
\text { complications } \\
\text { (\%) }\end{array}$ \\
\hline Krieg $^{13}$ & $\begin{array}{l}\text { Post-MAD (varus } \\
\text { group) }=4 \text { medial } \\
\text { (range: } 38 \text { medial-11 } \\
\text { lateral); post-MAD } \\
\text { (valgus group) }=0 \\
\text { (range: } 10 \text { medial-28 } \\
\text { lateral) }\end{array}$ & 41.8 & 12.5 \\
\hline Lenze $^{14}$ & $\begin{array}{l}\text { MAD } 1 \mathrm{~mm} \text { lateral } \\
\text { (12 lateral-12 } \\
\text { medial) }\end{array}$ & $\begin{array}{l}\text { Femur } 35, \\
\text { tibia } 48\end{array}$ & 27 \\
\hline Kirane $e^{15}$ & $\begin{array}{l}\text { Length: accuracy } \\
96 \% \text {, precision } 86 \% \text {, } \\
\text { angular deformity: } \\
1 \text { mm MAD (2-8) }\end{array}$ & NR & 28 \\
\hline Accadbled $^{16}$ & $\begin{array}{l}\text { Post-valgus } 3^{\circ} \\
\text { (range: } 0-5) \text {; post- } \\
\text { varus } 2^{\circ} \text { (range: } 0-5 \text { ) }\end{array}$ & $\begin{array}{l}\text { Femur } 73 \text {, } \\
\text { tibia } 83\end{array}$ & 15 \\
\hline lobst $^{17}$ & $\begin{array}{l}\text { Final LDFA } 88^{\circ} \text {, final } \\
\text { MAD within } 8 \mathrm{~mm} \\
\text { of goal in } 81 \% \text { of } \\
\text { patients }\end{array}$ & Femur 29.6 & 15 \\
\hline
\end{tabular}

MAD, mechanical axis deviation; Var, varus; Val, valgus; med, medial; lat, lateral; $\mathrm{BHI}$, bone healing index; Comp, complications, NR, not reported

angles of the affected segment ranged from 97 to $100 \%$. This discrepancy between a high accuracy in correcting the LDFA with a femoral osteotomy and restoration of the ideal MAD could have been secondary to joint line laxity and dependence on the patient positioning during the radiograph. The internal lengthening nail (ILN) has been shown in other studies to reestablish limb length with high accuracy and precision and low complication rates. ${ }^{15,23}$ In femur lengthening procedures, the ILN has been demonstrated to cause small lateral shifts in the mechanical axis without compromising limb function. ${ }^{24}$ The treatment of limb length discrepancies of the femur with concomitant angular or rotational deformities has also been successful with ILN, with minimal unwanted changes in bone alignment (Table 12). ${ }^{25}$

Of the surgical conditions we studied, the only significant factors that improved accuracy were increasing the osteotomy distance from joint line by over $10 \mathrm{~cm}$ and using at least one posterior blocking screw in the treatment of femur deformity/ length discrepancy. Postoperative MAD was slightly closer to goal $(p=0.017)$ in patients whose osteotomies were greater than 10 $\mathrm{cm}$ away from the joint line. However, in the same patients, the distance from the joint line did not improve the postoperative LDFA ( $p=0.48$ ) highlighting the inherent differences between MAD and joint orientation angles as reproducible metrics and bringing into question the clinical significance of the MAD finding. The presence of at least one posterior blocking screw decreased the change in the postoperative canal space after lengthening ( $p=$ $0.037)$ but did not affect the change in PDFA $(p=0.479)$. The need for an additional posterior femoral blocking screw depended upon surgeon preference and expert opinion. The use of more than one AP blocking screw did not improve accuracy of alignment in femurs or tibias. In a study on distal femoral deformity correction and lengthening with a retrograde IM nail, the authors found that the use of two or more blocking screws was associated with higher accuracy of the final alignment. ${ }^{17}$ In our study, the amount of lengthening did not have any effect on accuracy. The use of a posterior blocking screws in tibia surgery did not produce significant differences in the final alignment. In all of the above-mentioned comparisons between using $0,1,>1$ blocking screw, it must be emphasised that this was not a randomised analysis. When there was space to insert a blocking screw posterior to the nail, then the screw was used; and when there was no space for a blocking screw, the screw was not used. The results are technique dependent with the message that in order to replicate these findings, blocking screws are needed unless there is no room to place them because the adjacent cortex acts to block the nail from shifting. The senior authors strove to insert all blocking screws flush with the nail. The distance from the screw to the nail was a variable we did not measure in our research since there was minimal space between the nail and the screw.

In a similar study on internal lengthening nails without the use of a posterior blocking screw, $50 \%$ of tibial lengthenings developed flexion deformity at the osteotomy. ${ }^{26}$ Some patients in our study who underwent proximal tibial osteotomy sustained posterior cortical fracturing with proximal propagation. These patients experienced flexion deformity at the site of the osteotomy that increased during tibial lengthening. We did not alter our knee ROM program in response to flexion at the osteotomy site.

Across all our different metrics, the cases that had posterior cortical fractures with propagation had significantly more procurvatum at the final follow-up despite the appropriate use of blocking screws $(p=0.045)$. Based on these results, in cases where the fracture propagates proximally, the blocking screw must be assumed to be compromised and additional actions taken to prevent deformity. It should first be stated that performing an osteotomy with a Gigli saw will avoid this complication. Once the problem has occurred, an additional blocking screw can be inserted posterior to the nail to help prevent flexion. If the comminution is severe, then consideration should be given toward the use of a circular external fixator.

The functional and radiographic outcomes of the entire cohort were excellent and good supporting the clinical success of this method in deformity management. The use of IM nail is a generally safe method of osteosynthesis; however, known complications of the procedure include malalignment, infection, hardware failure, impaired bony healing, and neurovascular injuries. ${ }^{27}$ There were no infections, equipment failure, or postoperative pain requiring revision surgery in our study population. All of our patients reached union of bone in the osteotomy site, and no major complications were found. Four patients complained of significant pain in their follow-up. These patients suffered from chronic opioid addiction before their surgeries, and they were following up with a pain management physician at the time of data collection.

This is a retrospective study with inherent limitations in the level of evidence. The sample size was small, so claims of significance should be considered with caution. The variables that we selected to study were not tested in a randomised model with a control group. Therefore, the true impact of blocking screws on deformity was not able to be compared and studied. Further studies combining patients across multiple institutions would improve the power of this analysis and better evaluate the usefulness of the RROT as a teachable tool. 


\section{Conclusion}

The correction and prevention of deformity using IM nails with blocking screws guided by the RROT achieved accurate alignment in both femur and tibia surgery. The data suggest that a distal femoral osteotomy close to the knee joint may make alignment harder to control than an osteotomy $10 \mathrm{~cm}$ from the joint and that using a posterior blocking screw in the proximal tibia will improve final alignment, but the study lacks the power to make firm conclusions. There were with no major complications, and clinical outcomes were good to excellent supporting continued use of this surgical method.

\section{References}

1. Dodd L, Jackson M, Varma R. Poller blocking screws and Intramedullary nailing in tibial malunion. Ann R Coll Surg Engl 2007;89(8):816-818. DOI: 10.1308/rcsann.2007.89.8.816b.

2. Fragomen AT, Rozbruch SR. Retrograde magnetic internal lengthening nail for acute femoral deformity correction and limb lengthening. Expert Rev Med Devices 2017;14(10):811-820. DOI: 10.1080/17434440.2017.1378092.

3. Rozbruch SR. Adult posttraumatic reconstruction using a magnetic internal lengthening nail. J Orthop Trauma 2017;31(Suppl 2):S14-S19. DOI: $10.1097 /$ BOT.0000000000000843.

4. Fragomen AT, Rozbruch SR. Lengthening and deformity correction about the knee using a magnetic internal lengthening nail. SICOT J 2017;3:25. DOI: 10.1051/sicotj/2017014.

5. Fragomen AT, Rozbruch SR. Lengthening of the femur with a remotecontrolled magnetic intramedullary nail: retrograde technique. JBJS Essent Surg Techniq 2016;6(1):e2. DOI: 10.2106/JBJS.ST.15. 00069.

6. Chan DS, Nayak AN, Blaisdell G, et al. Effect of distal interlocking screw number and position after intramedullary nailing of distal tibial fractures: a biomechanical study simulating immediate weight-bearing. J Orthop Trauma 2015;29(2):98-104. DOI: 10.1097/ BOT.0000000000000195.

7. Stedtfeld H-W, Mittlmeier T, Landgraf $\mathrm{P}$, et al. The logic and clinical applications of blocking screws. JBJS 2004;86(Suppl 2):17-25. DOI: 10.2106/00004623-200412002-00004.

8. Furmetz J, Bosl S, Schilling J, et al. Blocking screws for alignment control in intramedullary limb lengthening. Injury 2017;48(7): 1597-1602. DOI: 10.1016/j.injury.2017.03.043.

9. Muthusamy S, Rozbruch SR, Fragomen AT. The use of blocking screws with internal lengthening nail and reverse rule of thumb for blocking screws in limb lengthening and deformity correction surgery. Strateg Trauma Limb Reconstr 2016;11(3):199-205. DOI: 10.1007/s11751-0160265-3.

10. Fabricant PD, Camara JM, Rozbruch SR. Femoral deformity planning: intentional placement of the apex of deformity. Orthopedics 2013;36(5):e533-537. DOI: 10.3928/01477447-20130426-11.

11. Paley D, Catagni MA, Argnani F, et al. Ilizarov treatment of tibial nonunions with bone loss. Clin Orthopaed Relat Res
1989;241(241):146-165. DOI: 10.1097/00003086-19890400000017.

12. Paley D. Normal lower limb alignment and joint orientation. Principles of deformity correction. Springer; 2002. pp. 1-18.

13. Krieg AH, Lenze U, Speth BM, et al. Intramedullary leg lengthening with a motorized nail: indications, challenges, and outcome in 32 patients. Acta Orthop 2011;82(3):344-350. DOI: 10.3109/17453674.2011.584209.

14. Lenze $U$, Hasler C, Krieg A. Ausgleich posttraumatischer Beinverkürzungen mit einem motorisierten intramedullären Nagel. Unfallchirurg 2011;114(7):604-610. DOI: 10.1007/s00113-010-1820-x.

15. Kirane YM, Fragomen AT, Rozbruch SR. Precision of the PRECICE internal bone lengthening nail. Clin Orthop Relat Res 2014;472(12):3869-3878. DOI: 10.1007/s11999-014-3575-0.

16. Accadbled F, Pailhé $R$, Cavaignac $E$, et al. Bone lengthening using the Fitbone ${ }^{\circledast}$ motorized intramedullary nail: the first experience in France. Orthopaed Traumatol Surg Res 2016;102(2):217-222. DOI: 10.1016/ j.otsr.2015.10.011.

17. lobst CA, Rozbruch SR, Nelson S, et al. Simultaneous acute femoral deformity correction and gradual limb lengthening using a retrograde femoral nail: technique and clinical results. J Am Acad Orthop Surg 2018;26(7):241-250. DOI: 10.5435/JAAOS-D-16-00573.

18. Ricci WM, O'boyle M, Borrelli J, et al. Fractures of the proximal third of the tibial shaft treated with intramedullary nails and blocking screws. J Orthop Trauma 2001;15(4):264-270. DOI: 10.1097/00005131200105000-00005.

19. Gao KD, Huang JH, Li F, et al. Treatment of aseptic diaphyseal nonunion of the lower extremities with exchange intramedullary nailing and blocking screws without open bone graft. Orthopaed Surg 2009;1(4):264-268. DOI: 10.1111/j.1757-7861.2009.00041.x.

20. Bong MR, Koval KJ, Egol KA. The history of intramedullary nailing. Bull NYU Hosp Jt Dis 2006;64(3-4):94-97.

21. Ostrum RF, Maurer JP. Distal third femur fractures treated with retrograde femoral nailing and blocking screws. J Orthop Trauma 2009;23(9):681-684. DOI: 10.1097/BOT.0b013e3181ad61f2.

22. Gavaskar AS, Chowdary N. Blocking screws: an adjunct to retrograde nailing for distal femoral shaft fractures. J Orthopaed Surg 2013;21(2):158-162. DOI: 10.1177/230949901302100208.

23. Kulkarni SG, Varshneya A, Kulkarni S, et al. Intramedullary nailing supplemented with poller screws for proximal tibial fractures. J Orthop Surg (Hong Kong) 2012;20(3):307-311. DOI: 10.1177/230949901202000308.

24. Burghardt R, Paley D, Specht $S$, et al. The effect on mechanical axis deviation of femoral lengthening with an intramedullary telescopic nail. J Bone Joint Surg Br 2012;94(9):1241-1245. DOI: 10.1302/0301620X.94B9.28672.

25. Rozbruch SR, Fragomen AT. Lengthening of the femur with a remotecontrolled magnetic intramedullary nail: antegrade technique. JBJS Essent Surg Tech 2016;6(1):e2. DOI: 10.2106/JBJS.ST.0.00063.

26. Horn J, Hvid I, Huhnstock S, et al. Limb lengthening and deformity correction with externally controlled motorized intramedullary nails: evaluation of 50 consecutive lengthenings. Acta Orthop 2019;90(1):81-87. DOI: 10.1080/17453674.2018.1534321.

27. Hessmann MH, Rommens PM. Intramedullary Nailing: A Comprehensive Guide. Springer; 2015. 